\title{
O Ensino da Matemática, a aprendizagem e o fracasso escolar: uma análise dessas relações no Ensino Médio Integrado de uma instituição da rede federal de Ensino Básico, Técnico e Tecnológico
}

\author{
The Teaching of Mathemmatics, learning and school failure: an analysis of the relationships \\ in the Inyegrated High School of an institution of the federal network of basic Education, \\ technical and technological
}

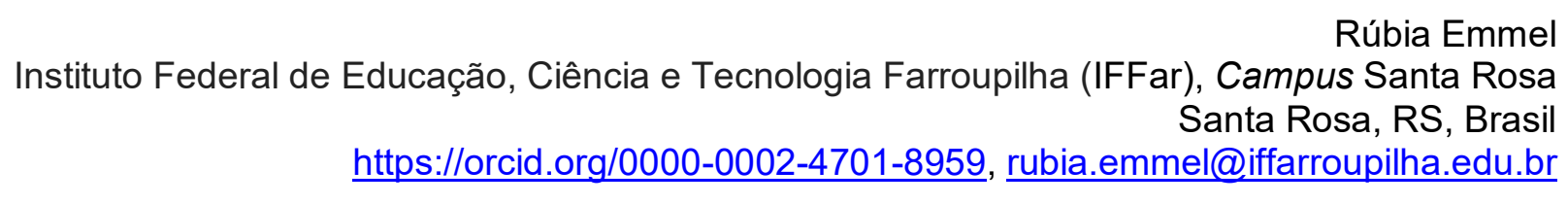

Paola de Costa

Instituto Federal de Educação, Ciência e Tecnologia Farroupilha (IFFar), Campus Santa Rosa

Santa Rosa, RS, Brasil

https://orcid.org/0000-0001-6578-3032, decostapaola@gmail.com

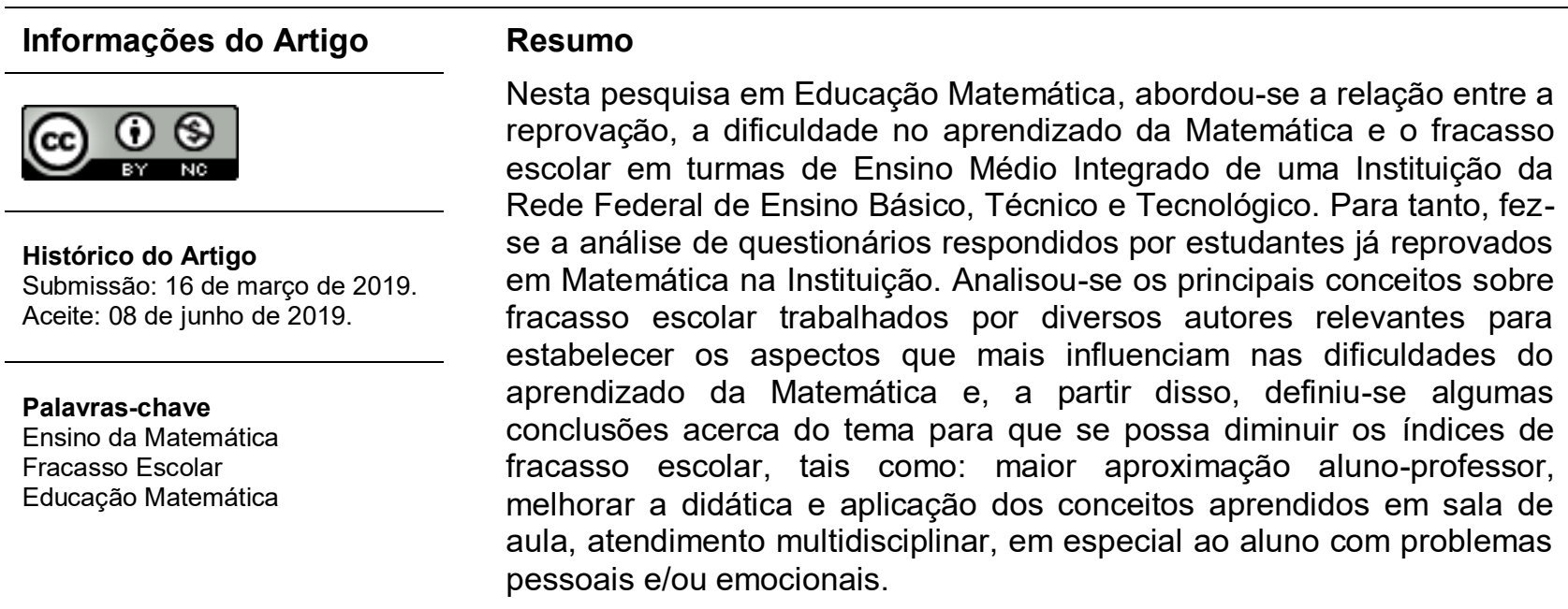

\begin{tabular}{ll}
\hline Keywords & Abstract \\
Learning Mathematic, & In the present research in Mathematics Education was briefly addressed \\
School Dropout & on the relationship between the difficulty in learning mathematics and \\
Mathematics Education & school failure in integrated High School classes of an institution of the \\
federal network of technical and technological basic education. For that, \\
the analysis of questionnaires answered by students who have already \\
failed in the mathematics of the institution besides other documents \\
provided by the same institution. It was analyzed the main concepts \\
about school failure worked by several relevant authors to establish the \\
aspects that most influence in the difficulty in the learned Mathematics, \\
and from this, some conclusions were defined about the subjects, so \\
that one can reduce the indices of the school failure, such as greater \\
student-teacher approximation, better didactics and application of \\
concepts learned in the classroom, multidisciplinary care, especially to \\
the student with personal and / or emotional problems.
\end{tabular}




\section{Introdução}

Esta pesquisa em Educação Matemática teve como objetivo compreender a relação entre a dificuldade no aprendizado da Matemática e o fracasso escolar em turmas de Ensino Médio Integrado ao Técnico, de uma Instituição da Rede Federal de Ensino Básico, Técnico e Tecnológico. O estudo foi feito através de análise documental e de um questionário aos estudantes. O fracasso escolar é conceituado por Damasceno e Negreiros (2018, p. 75) como "a reprovação e/ou evasão do aluno em algum momento durante o percurso escolar". Já, para outros autores, o fracasso escolar é um conceito ainda mais abrangente, compreendendo, também, conforme os estudos de Pezzi e Marin (2017), fatores como baixo rendimento escolar, distorção idade-série e dificuldades de aprendizagem.

Conforme Barroso et al. (2016), especialmente na disciplina de Matemática, o fracasso escolar ocorre por fatores relacionados a problemas cognitivos e de aprendizagem. Além disso, baseado nas mesmas referências, as autoras, em suas pesquisas, evidenciam que a rejeição atribuída a referida disciplina, se dá, em partes, pela forma em que os alunos se relacionam com a Matemática, visto que trata-se de um componente curricular que necessita despertar a consciência crítica do aluno.

Não obstante isso, as autoras argumentam que o conservadorismo na forma de ensinar conhecimentos matemáticos é um dos fatores que contribuem para o fracasso escolar. Conforme essas autoras, ao apenas repetir e memorizar conceitos, sem de fato entender seu significado, o aluno deixa de compreender a matéria a partir de um pensamento crítico, passando a apenas repetir conceitos previamente repassados a ele.

Para que a pesquisa fosse desenvolvida, foi abordado o seguinte problema: quais os fatores que influenciam no fracasso escolar dos estudantes relacionados ao ensino e a aprendizagem da Matemática em turmas de Ensino Médio Integrado ao Técnico, de uma instituição da Rede Federal de Ensino Básico, Técnico e Tecnológico?

Considerando que o fracasso escolar pode decorrer dos mais diversos fatores, extrínsecos ou intrínsecos, o estudo da relação entre o fracasso escolar e o ensino da Matemática se fez pertinente para que se possa compreender os reais motivos que levam os alunos à evasão e/ou insucesso escolar, especialmente no Ensino Médio Integrado ao Técnico de uma instituição da Rede Federal de Ensino Básico, Técnico e Tecnológico, sendo o estudo de caso ao qual o presente projeto se propôs analisar.

A partir das leituras em Pezzi e Marin (2017), compreende-se que para além da dificuldade cognitiva e a rejeição em relação à Matemática que muitos alunos apresentam, alguns fatores, como os investigados pelas autoras, contribuem para o fracasso escolar, tais como: o meio social, a violência, a gravidez na adolescência, problemas psicológicos, fatores socioeconômicos, dentre tantos outros. 
Acreditou-se que este tema é relevante, pois o Ensino Médio Integrado ao Técnico possui uma carga horária mais elevada, com mais componentes curriculares, o que exige maior tempo de estudos. Assim, com esta investigação foi possível compreender as concepções e as dificuldades dos estudantes sobre a Matemática. Compreendeu-se que a relevância desta pesquisa esteve em identificar os possíveis fatores e as dificuldades que levam os estudantes a reprovação e ao fracasso escolar em Matemática.

Para possibilitar o desenvolvimento da pesquisa, buscou-se compreender a relação entre a reprovação, as dificuldades de aprendizagem em Matemática e o fracasso escolar em turmas de Ensino Médio Integrado de uma instituição da Rede Federal de Ensino Básico, Técnico e Tecnológico e, para isso, identificou-se os fatores que influenciam na dificuldade dos alunos em aprender Matemática. Coletou-se e analisou-se os dados de reprovação do componente curricular Matemática, em turmas de Ensino Médio Integrado de uma instituição da rede Federal de Ensino Básico, Técnico e Tecnológico. Tal análise foi realizada por meio de questionário, a relação entre o fracasso escolar e o insucesso na aprendizagem Matemática dos estudantes.

\section{Referencial teórico}

Desde os tempos dos filósofos pitagóricos, como nos traz Rivièri (1995), construiu-se uma cultura que persiste até os dias atuais: a cultura de que a Matemática se constitui de um saber dedutivo, revestindo-se de certo caráter elitista e seletivo, de forma que a aprendizagem Matemática é privilégio de alguns, com capacidades intelectuais superiores, fazendo com que muitas pessoas rejeitem tal matéria sem ao menos tentar compreendê-la.

A fim de refletir sobre tal temática, realizou-se uma experiência, posteriormente publicada no Informe Cockcroft (1985 apud RIVIĖRI, 1995), na qual foram entrevistados apenas adultos, com o intuito de compreender suas deficiências no aprendizado da Matemática e suas ações para enfrentá-las. Conforme Rivièri (1995), tal investigação mostrou que metade dos entrevistados simplesmente negava-se a participar, pelo simples fato de a pesquisa questionar suas habilidades Matemáticas.

Diante disso, surgem alguns questionamentos, tais como: a dificuldade de aprendizagem referente à Matemática se dá por quais motivos? Quais os fatores que levam o insucesso em sua aprendizagem? Qual a relação entre o fracasso escolar e o ensino da Matemática?

Considerando estas problemáticas enquanto dilemas na formação inicial e continuada de professores, esta pesquisa buscou dados a partir de uma realidade escolar, buscando compreender as relações entre fracasso escolar e ensino de Matemática. Entre as principais autorias da temática em estudo neste artigo, percebemos que são inúmeros os fatores que levam ao fracasso escolar, porém quanto a sua relação com a dificuldade de aprender matemática, Weber e Lopes (2013, p. 257) citam alguns como "problema psíquico, problema técnico, questão institucional e questão política". 


\subsection{Fracasso escolar e Matemática: o que as pesquisas nos dizem?}

As pesquisas de Pacheco e Andreis (2018) demonstram o descontentamento na aprendizagem da Matemática, e afirmam que ocorrem há muito tempo. Conforme as autoras, esse descontentamento verifica-se tanto por parte dos alunos, quanto por parte dos professores, o que também vem sendo demonstrado pelos órgãos responsáveis pelas avaliações tanto nacionalmente como internacionalmente, como, por exemplo, o Sistema Nacional de Avaliação da Educação Básica (SAEB).

Os problemas relacionados à aprendizagem da Matemática surgem já nos primeiros contatos do aluno com a matéria, conforme Pacheco e Andreis (2018), ainda nos anos iniciais, seja por despreparo didático do professor ou por insuficiente atenção do aluno relativamente à matéria, o consciente de muitos alunos fica condicionado no sentido de que a Matemática é praticamente impossível de ser compreendida, deixando marcas negativas para sempre.

Conceituado por Weber e Lopes (2013, p. 2) como "resultados insatisfatórios, distorção idade- série/ano, reprovação, baixo rendimento, evasão escolar", o fracasso escolar mostra-se como um dos principais desafios atuais aos profissionais de ensino, em especial, aos professores de Matemática. Segundo as referidas autoras, em pesquisa realizada no ano de 2010 pelo Instituto Brasileiro de Geografia e Estatística (IBGE), "as taxas de distorção idade-série/ano $(23,4 \%)$, reprovação $(10,3 \%)$ e abandono escolar $(3,1 \%)$ no ensino fundamental são significativas e preocupantes" (WEBER; LOPES, 2013, p. 2).

O fracasso escolar já faz parte da história da educação pública brasileira, e a sua relação com a dificuldade na aprendizagem da Matemática é inegável, e isso ficou mais visível após as avaliações propostas pelo Instituto Nacional de Estudos e Pesquisas Educacionais Anísio Teixeira (INEP), especialmente nos anos iniciais do Ensino Fundamental. Conforme Weber e Lopes (2013, p. 257): "os índices de desempenho em relação à Matemática são considerados insuficientes, e isso é justificado por ser um componente curricular de difícil compreensão pelos alunos, e este fato pode se tornar um obstáculo para o ensino e aprendizagem da Matemática".

Alguns dados sobre evasão escolar no Brasil são trazidos por Barroso et al. (2016, p. 1-2), e transcritos a seguir:

Segundo o Fundo Nacional das Nações Unidas para a Infância - UNICEF 2011, $45,6 \%$ das crianças brasileiras (menores de 18 anos) estavam vivendo na pobreza. São cerca de 21 milhões de adolescentes com idade entre 12 e 17 anos, no Brasil, sendo que a cada 100 estudantes que entram no ensino fundamental, somente 59 terminam o $9^{\circ}$ ano e apenas 40 , o ensino médio. O instituto Nacional de Estudos e Pesquisas Educacionais (INEP) em 2014 confirmou o alto índice de evasão, revelando, nos anos iniciais, a taxa de reprovação de $6,2 \%$ que corresponde a 969.540 estudantes reprovados e apresenta uma taxa de $1,1 \%$ de evasão, o que representa 170.440 abandonos. Já nos anos finais, estes índices representam, respectivamente $11,7 \%(1.489 .598)$ e $3,5 \%$ (450.317).

$\mathrm{Na}$ tentativa de redução desses números, Damasceno e Negreiros (2018, p. 82) trazem algumas sugestões, dentre elas: "o aprimoramento contínuo das técnicas de ensino dos 
professores, além de uma maior sensibilidade por parte destes para sentir a raiz das dificuldades dos alunos". A partir da percepção de alunos com dificuldades de aprendizagem em Matemática é importante o atendimento e acompanhamento do aluno por equipe multidisciplinar.

\subsubsection{As dificuldades de aprendizagem em Matemática}

Uma das dificuldades de aprendizagem em relação à Matemática é a discalculia que, conforme Rivièri (1995), apresenta-se como uma pequena alteração neurológica capaz de impedir ou dificultar a aprendizagem das operações matemáticas mais elementares. Conceitua-se como "discalculia específica de evolução" sugerindo que esta tem estrita relação com "dificuldades em funções visual-espaciais dependentes dos lóbulos parietais" (p. 135). Dessa forma, a dificuldade de aprendizagem decorrente da discalculia "seria devido a uma alteração genética ou congênita das zonas cerebrais que constituem o substrato anatômico-fisiológico da maturação das capacidades matemáticas" (p. 135).

Além das dificuldades cognitivas relacionadas com distúrbios neurológicos, autores como Pacheco e Andreis (2018) trazem outros aspectos que contribuem para o fracasso escolar: sociais, familiares e de relação aluno-professor. Em suas pesquisas, Pacheco e Andreis (2018) apresentam que as experiências familiares, sejam elas positivas ou negativas, podem influenciar a criança a desenvolver um sentimento de rejeição à Matemática, antes mesmo de ela ter contato com a matéria, pois "a partir dessas vivências, a criança pode desenvolver uma baixa autoestima e julgar-se incapaz de compreender a Matemática" (p. 106).

Outro fator investigado por Pezzi e Marin (2017), que tem associação direta com o desempenho do aluno em relação à Matemática, é a metodologia do professor nas aulas, que pode influenciar positivamente ou negativamente a aprendizagem de seus alunos. Compreendese que o professor torna-se motivador de seus alunos, contextualizando e problematizando o interesse deles pela Matemática, para isso pode ser criativo, criar condições para chamar a atenção e curiosidade do aluno, usando de metodologias mais ativas, tais como uso da tecnologia e jogos que auxiliam na aprendizagem da Matemática.

Dessa forma, percebe-se que os mais variados fatores podem influenciar direta ou indiretamente a dificuldade de aprendizagem da Matemática, levando muitas vezes ao fracasso escolar. O que cabe às pesquisas, conforme Pezzi e Marin (2017), é tentar estabelecer quais fatores são esses e as formas de tentar reduzir esses problemas e, consequentemente, diminuir os índices de fracasso escolar.

\section{Metodologia}

A presente pesquisa em educação caracterizou-se pela abordagem qualitativa, considerando que:

Na pesquisa qualitativa o pesquisador procura reduzir a distância entre a teoria e os dados, entre o contexto e a ação, usando a lógica da análise fenomenológica, 
isto é, da compreensão dos fenômenos pela sua descrição e interpretação. As experiências pessoais do pesquisador são elementos importantes na análise e compreensão dos fenômenos estudados. (TEIXEIRA, 2006, p. 137).

Além de ser caracterizada por seu aspecto qualitativo, foi realizada por meio de um estudo de caso. Este, aliás, foi caracterizado por um estudo de um caso específico, singular, de interesse dos pesquisadores. Para tanto, teve seus contornos bem delimitados que foram desenvolvidos no decorrer do trabalho (LÜDKE; ANDRÉ, 1986).

Tratou-se de um estudo de caso, pois a investigação foi realizada em uma instituição de ensino, em um curso ofertado por esta instituição, considerando que foram entrevistados os estudantes que reprovaram em Matemática em turmas de Ensino Médio Integrado ao Técnico.

Como instrumentos de coleta de dados desta pesquisa, tivemos os dados documentais fornecidos pela Secretaria de Registros Escolares, do Serviço de Apoio Pedagógico (SAP) e do Centro de Assistência Estudantil (CAE), sendo estes documentos os boletins dos estudantes, os diários dos professores, atas de conselhos de classe, e atas de atendimento de estudantes. Ainda para a coleta de dados foi elaborado um questionário, com questões abertas, para os estudantes que reprovaram em Matemática.

Por meio dos dados documentais coletados foram constituídas tabelas das reprovações que foram analisadas e permitiram ainda a análise de conteúdo do questionário. Conforme Lüdke e André (1986), a análise documental busca identificar informações a partir de hipóteses propostas. Para as autoras, este método de análise é interessante quando o pesquisador quer estudar o problema a partir da expressão do próprio indivíduo.

Para a análise de conteúdo, as mesmas autoras utilizam algumas estratégias, tais como: "delimitação progressiva do foco de estudo, formulação de questões analíticas, o aprofundamento de revisão da literatura, o uso extensivo de comentários ao longo da coleta" (LÜDKE; ANDRÉ, 1986, p. 46). O conteúdo analisado pelo presente projeto é produto dos questionários aplicados aos estudantes ou egressos de uma Instituição Federal de Ensino Básico, Técnico e Tecnológico. Tal análise consiste em:

[...] trabalhar todo o material obtido durante a pesquisa, ou seja, os relatos de observação, as transcrições de entrevistas, as análises de documentos e as demais informações disponíveis. A tarefa de análise implica, num primeiro momento, a organização de todo o material, dividindo-o em partes, relacionando essas partes e procurando entre elas tendências e padrões relevantes. Num segundo momento, essas tendências e padrões serão reavaliados, buscando-se as relações e inferências num nível mais elevado. (LÜDKE, ANDRÉ, 1986, p. 45).

Como material de análise, foi elaborada uma tabela com os índices de reprovação em Matemática nas turmas do Ensino Médio da instituição referida nos anos de 2015 a 2017. A partir dos dados obtidos, foi aplicado um questionário aos alunos reprovados na matéria, contendo 6 questões abertas:

1. Idade e série do Ensino Médio em que se encontra.

2. Em quais disciplinas você já reprovou. 
3. Apresenta dificuldade de aprendizagem Matemática?

4. Qual a sua relação com a Matemática?

5. A que fator você atribui o insucesso na aprendizagem da Matemática?

6. O que você acredita que pode ser feito para que as aulas de Matemática do Ensino Médio tenham melhor aproveitamento e, assim, maior rendimento?

\section{Resultados e discussões}

A fim de tentar compreender os motivos que levam ao fracasso escolar, passaremos à análise dos dados documentais obtidos junto a Secretaria de Registros Escolares, do Serviço de Apoio Pedagógico (SAP) e do Centro de Assistência Estudantil (CAE).

No ano de 2015, podemos observar que, em um total de 92 alunos cursando $01^{\circ}$ ano do Ensino Médio, houve 20 reprovações e 6 cancelamentos e transferências. Destas 20 reprovações, 6 ocorreram por não atingir a média em matemática ( 7 pontos), mas também em outras matérias, tais como Física e Química. No mesmo ano, para a série analisada, 3 alunos foram aprovados pelo Conselho de Classe em Matemática, que consiste numa reunião de professores de todas as matérias para avaliar se o aluno possui condições de avançar de série letiva, tendo aprendido o essencial, ainda que não alcançando a média da escola, considerando o total de aprovações nas demais disciplinas.

Nas turmas de $2^{\circ}$ ano do Ensino Médio Integrado do ano de 2015, de um total de 65 alunos, houve 2 reprovações e 1 cancelamento e transferência. Já os alunos da $3^{a}$ série do Ensino Médio daquele ano, em um total de 68 alunos todos foram aprovados, podemos refletir sobre o fato de este ser o último ano do Ensino Médio, e não haver reprovações, ou seja, a opção pela não retenção do aluno na Educação Básica.

Já no ano de 2016, no $1^{\circ}$ ano do Ensino Médio, de um total de 100 alunos, houve 18 reprovações e 6 cancelamentos e transferências. Um aluno aprovado pelo Conselho em Matemática, considerando sua aprovação nas demais disciplinas. No $2^{\circ}$ ano do Ensino Médio DE 2016, de 66 alunos matriculados, houve 6 reprovações, sendo 4 em Matemática, além de outras matérias, e 2 cancelamentos e transferências. Houve, na mesma série, dois alunos aprovados pelo Conselho em Matemática. No $3^{\circ}$ ano, ainda, de 62 alunos, ocorreram 2 reprovações e nenhum cancelamento e transferência.

No ano de 2017, cursavam, o $1^{\circ}$ ano do Ensino Médio, 93 alunos, dos quais 16 reprovaram, sendo uma aluna no componente curricular de Matemática, 6 alunos cancelaram e transferiram suas matrículas, uma aluna foi aprovada pelo Conselho em Matemática. Já no $2^{\circ}$ ano do Ensino Médio de 2017, de um total de 83 alunos, 9 reprovaram, dos quais duas reprovações ocorreram no componente de Matemática, e 4 transferências. Da mesma forma, no $3^{\circ}$ ano, de 57 alunos, não houve reprovações e ocorreu apenas um cancelamento e transferência. 
Conforme Reali (1997), três aspectos gerais podem ajudar a compreender os índices de fracasso escolar, quais sejam:

A primeira refere-se a ideia de que os professores, ao olharem seus alunos, através de atributos externos - raça, etnia, gênero, linguagem, classe social ou deficiências -, devem focalizar, em contrapartida, seu potencial como aprendizes. A segunda diz respeito ao fato de que dentre suas responsabilidades está a de realizar um trabalho sério com todos os alunos, independente dos desempenhos passados e da aparente capacidade para compreender um dado conteúdo, tendo como perspectiva sua aprendizagem. E, por último, os professores devem acreditar e comunicar aos seus alunos suas expectativas numa perspectiva de que todos podem aprender independente do conteúdo incluído no currículo escolar. (REALI, 1997, p. 174).

Para Baião (2015, p. 6), é necessário estudar o fracasso escolar considerando o aluno como "sujeito-aprendiz que se constrói também por sua singular apropriação do mundo". Ainda, para a mesma autora, não existe fracasso escolar, o que existe são alunos em situação de fracasso. O que também pode ser identificado nas afirmações de Barroso et al. (2016, p. 6):

Há fracasso na escola quando o rendimento é baixo, quando a adaptação social é deficiente, e também quando se destrói a autoestima do aluno. Deve-se aprender na escola conhecimentos e deve-se aprender a viver de acordo com um mínimo de normas compartilhadas, mas a escola também deve inculcar em seus alunos confiança neles mesmos, deve-lhes dar um vivo sentimento de valor, de capacidade, de força, de certeza que podem conseguir muitas das coisas que se propõe. A escola não deve criar indivíduos apáticos, desanimados ou desmoralizados [...]. Não há pior fracasso escolar que produzir alunos com tão baixa autoestima.

Para compreender tais aspectos que influenciam no fracasso escolar, a partir da leitura em Reali (1997), é imprescindível o desenvolvimento de indicadores educacionais, que atuam não somente como um exercício técnico, mas também político. Desta forma, um indicador não é apenas uma expressão numérica, vez que sua análise possibilita descrições sobre desempenho e comportamento de um sistema educacional que podem ser utilizadas como material de informação para aqueles que decidem as políticas educacionais e todos aqueles envolvidos nessa realidade, como professores, pais, aluno, e a sociedade em geral. A principal função dos indicadores é, justamente, fornecer dados para a compreensão do fenômeno "fracasso escolar" e possibilitar novas visões e novos métodos para tentar solucionar este problema. Os dados descritos anteriormente estão representados no gráfico da Figura 1.

Para melhor compreender os motivos que levam ao fracasso escolar ou à reprovação foi elaborado um questionário, todos os estudantes ou egressos incluindo os cancelamentos, transferências e reprovações, foram convidados a responder o questionário, porém apenas sete alunos do Ensino Médio que já reprovaram na disciplina de Matemática, preencheram o questionário. Em relação às dificuldades de aprendizagem Matemática, quatro estudantes apresentam de forma geral e outros quatro estudantes, às vezes.

Quando questionados sobre a sua relação com a Matemática, cinco estudantes responderam que gostam apenas de alguns conteúdos, e três estudantes responderam que não gostam da matéria. Em relação à questão: "A que fator você atribui o insucesso/dificuldade na 
aprendizagem da Matemática?"; cinco estudantes responderam que não gostam de estudar Matemática, devido ao fato de não entendê-la; outros três estudantes. Responderam que as aulas são pouco atrativas (1), dificuldade em aplicar os conceitos e cálculos na vida (1), falta de didática do professor (1).

Figura 1 - Matrículas de Alunos, Reprovações, cancelamentos e transferências.

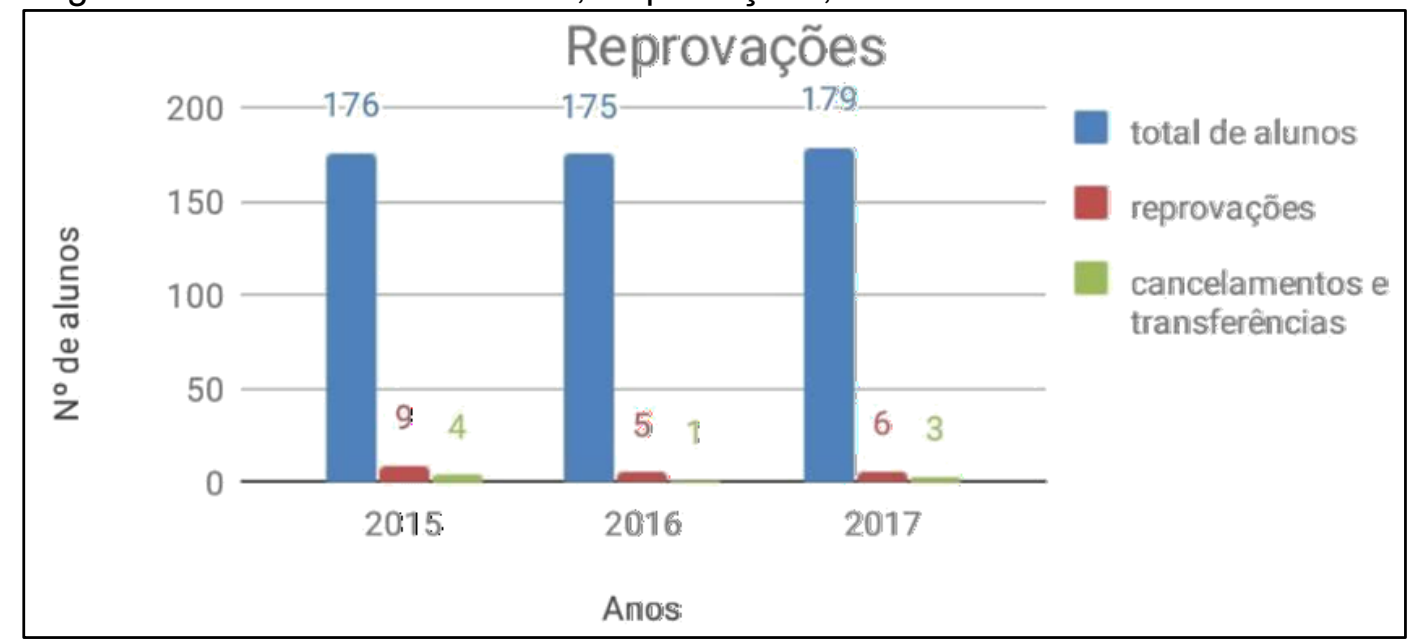

Fonte: Dados da pesquisa (2018).

Quando questionados sobre "o que você acha que pode ser feito para que as aulas de Matemática tenham melhor aproveitamento e assim maior rendimento?" As respostas foram: "mais aulas de reforço (1), aulas mais dinâmicas (2), maior exemplificação dos conceitos com aplicação do conteúdo na prática (3), e também mostrar mais formas de resolver as questões com outros caminhos tornando-os mais fáceis e diretos (2)". Percebe-se que a maioria dos estudantes referiu a importância do papel do professor neste processo de aprendizagem, e ainda das metodologias de ensino em Matemática utilizadas pelos professores.

Uma das possibilidades de reflexão sobre as metodologias de ensino em Matemática estaria nos instrumentos utilizados para as avaliações da aprendizagem ou do rendimento escolar: as provas. A partir da leitura de Rivière (1995) compreende-se que estes instrumentos não podem se limitar a apontar os erros cometidos, indo além, podem ser utilizados como "diagnósticos cognitivos" (p. 142), ainda que parcialmente dos processos responsáveis pelos erros, passando o aluno de mero receptor passivo, para um "construtor ativo do conhecimento" (p. 142), assim os erros podem ser considerados produtos de uma construção ativa do conhecimento.

Desse modo, "o professor deve estar atento às suas motivações e às diversas problemáticas que podem estar atreladas ao desempenho de seus alunos, para que ele não se volte às práticas patologizantes e medicalizantes construídas com o passar dos anos." (DAMASCENO; NEGREIROS, 2018, p. 84). Também Riviére (1995, p. 149) refere-se a árdua missão dos professores de Matemática, ao ignorar as capacidades de abstração dos estudantes: 
Naturalmente, o bom professor de matemática emprega procedimentos que facilitem a abstração e se esforça (especialmente no ensino primário) para ancorar os conceitos matemáticos na experiência de ver como há um grupo de alunos que "perdem pé" e acumulam "lacunas de conhecimento", devido à influência conjunta das exigências de abstração matemática, sua estrutura fortemente hierárquica e a necessidade de ensinar a grupos. O professor vê-se, então, diante de um difícil dilema: deve voltar atrás, até chegar ao nível real de conhecimentos desses alunos atrasados? E o que fazer, enquanto isso com os outros alunos?

Neste artigo apenas oferecemos indicações mais gerais sobre a resposta a estas perguntas, que nos ajudam a refletir sobre o fracasso escolar, as dificuldades de aprendizagem dos estudantes e o ensino de Matemática. Nesta perspectiva, o professor pode desafiar-se a contribuir com a prevenção dos problemas já referidos nas respostas dos estudantes, e colaborar para que os estudantes compartilhem os sucessos escolares, a partir de satisfações na experiência Matemática. Entre as metodologias que podem contribuir para aprendizagem dos estudantes estaria a "aprendizagem baseada na resolução de problemas" (RIVIÈRE, 1995, p. 156), e não unicamente, a resolução de cálculos escritos.

A partir disso, pode-se perceber a importância do papel que o professor exerce diretamente para o melhor aprendizado do aluno. Para Damasceno e Negreiros (2018), as práticas pedagógicas dos professores são, muitas vezes, produtos dos modelos sociais vigentes e de formas de atuação muito enrijecidas e que ainda se prendem aos moldes tradicionais educativos, pouco atrativas para sujeitos que vivenciam transformações sociais tão significativas, especialmente nas últimas décadas. Acompanhar essas transformações influencia diretamente nos índices de sucesso escolar. É importante que tenhamos mais pesquisas para analisar os fatores que levam alguns alunos ao fracasso escolar nessa disciplina, considerando também as dificuldades dos professores ao ensinar Matemática.

\section{Conclusões}

Por meio da presente pesquisa, pode-se, ainda que de maneira breve, identificar alguns aspectos que influenciam no insucesso na aprendizagem da Matemática. Pode-se inferir, diante das pesquisas realizadas e das respostas obtidas por meio dos questionários que os estudantes responderam, que alguns alunos disseram não gostar de estudar a matéria por não entendê-la, aulas pouco atrativas e falta de aplicabilidade dos conceitos aprendidos em sala de aula no dia a dia do aluno. Sabe-se que há inúmeros fatores que podem contribuir para o fracasso escolar, este recorte de pesquisa buscou identificar e entender alguns destes, através de dados coletados, junto às turmas Ensino Médio Integrado.

A partir da pesquisa realizada, pode-se concluir que há muito a fazer para buscar índices menores de fracasso escolar relacionados a aprendizagem da Matemática. Alguns deles podem ser, por parte do professor, buscar conhecer a realidade do aluno, estabelecendo uma relação mais próxima com ele, também, buscar elaborar aulas mais didáticas, atrativas e procurando 
exemplificar os conceitos passados em sala de aula de forma que o aluno consiga representá-los, a fim de não apenas decorar e repetir conceitos, mas efetivamente, compreendê-los.

Sendo assim, esta pesquisa demonstra a necessidade reflexão dos professores sobre suas práticas e ações na Educação Básica, a fim de reconhecer o erro como processo e possibilidade de aprendizagem, em que a metodologia da aprendizagem, a partir da resolução de problemas no cotidiano dos estudantes, seja de fato utilizada nas aulas de Matemática. Ainda, podem os professores utilizar diferentes tecnologias da informação e comunicação em suas aulas, como a utilização de softwares para demonstrar a solução dos problemas matemáticos. Um exemplo é a utilização do software Geogebra, para projetar gráficos de funções de $2^{\circ}$ grau, uma vez que o uso da tecnologia em sala de aula pode contribuir para o interesse do aluno na matéria abordada, já que as novas gerações de estudantes e adolescentes estão inseridos no mundo digital.

Também conclui-se que um dos aspectos relevantes que influenciam na aprendizagem da Matemática são problemas pessoais, emocionais e familiares. Para tanto, reforça-se a importância do atendimento multidisciplinar ao aluno, para que este possa contornar problemas externos que estejam interferindo em seu rendimento escolar.

Enfatiza-se que as pesquisas acerca do fracasso escolar e a dificuldade no aprendizado da Matemática são capazes de motivar inúmeras outras pesquisas, nas mais diversas áreas de conhecimento. Considerando que diversos fatores são capazes de influenciar o rendimento escolar do estudante, tais como: problemas pessoais, emocionais, cognitivos, familiares, de ordem social, do meio em que ele está inserido, entre tantos outros.

\section{Referências}

BAIÃO, D. V. Fracasso escolar nos sextos anos do ensino fundamental II, em Matemática: causas, consequências e desafios. In: ENCONTRO BRASILEIRO DE ESTUDANTES DE PÓS GRADUAÇÃO EM EDUCAÇÃO MATEMÁTICA, 19, 2015, Minas Gerais. Anais... Juiz de Fora: Universidade Federal de Juiz de Fora. Sessão D, p. 1-9.

BARROSO, E. de S.; JESUS, J. I. de; MOURA, D. A. da S. Ensino da matemática: falhas e insucessos, um estudo de caso em uma escola de Pará, de Minas Gerais-MG. In: ENCONTRO NACIONAL DE EDUCAÇÃO MATEMÁTICA, 12, 2016, São Paulo. Anais... São Paulo: Sociedade Brasileira de Educação Matemática, p. 1-12.

DAMASCENO, M. A.; NEGREIROS, F. Professores, fracasso e sucesso escolar: um estudo no contexto educacional brasileiro. Revista de Psicologia da IMED, Passo Fundo, v. 10, n. 1, p. 7389, 2018.

LÜDKE, M.; ANDRÉ, M. E. D. A. Pesquisa em educação: abordagens qualitativas. São Paulo: EPU, 1986.

PACHECO, M. B.; ANDREIS, G. da S. L. Causas das dificuldades de aprendizagem em Matemática: percepção de professores e estudantes do $3^{\circ}$ ano do Ensino Médio. Revista Principia, João Pessoa, n. 38, p. 105-119, 2018. 
PEZZI, F. A. S.; MARIN, Â. H. Fracasso Escolar na Educação Básica: revisão sistemática da literatura. Temas em Psicologia, Ribeirão Preto, v. 25, n. 1, p. 1-15, 2017.

REALI, A. M. de M. R. Conhecendo os alunos por meio de indicadores educacionais: algumas reflexões. In: ABRAMOWICZ, A.; MOLL, J. (Orgs.). Para além do fracasso escolar. 4. ed. Campinas: Papirus, 1997.

RIVIĖRE, A. Problemas e dificuldades da aprendizagem matemática: uma perspectiva cognitiva. In: COLL, C.; PALACIOS, J.; MARCHESI, A. (Orgs.). Desenvolvimento Psicológico e educação: necessidades educativas especiais e aprendizagem escolar. v. 3. Porto Alegre: Artes Médicas, 1995.

TEIXEIRA, E. As três metodologias: acadêmica, da ciência e da pesquisa. 2. ed. Petrópolis: Vozes, 2006.

WEBER, T. M.; LOPES, A. R. L. V. Educação matemática escolar: o fracasso do aluno ou do sistema? In: CONGRESSO NACIONAL DE EDUCAÇÃO - EDUCERE, 11, 2013, Paraná. Anais... Curitiba: Pontifícia Universidade Católica do Paraná, p. 25774-25782. 